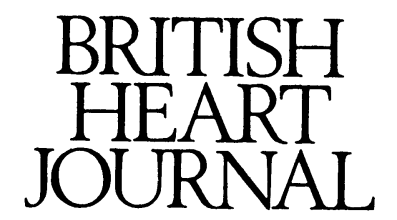

\title{
Editorial
}

\section{Is cardiac rehabilitation necessary?}

Eight to $38 \%$ of patients do not return to work after myocardial infarction though many of them seem physically capable of resuming employment. ${ }^{1}$ The cost of myocardial infarction is high and is mainly the result of vocational disability. In the 1970 s and 1980 s many studies were designed to test the premise that rehabilitation after infarction improves the patient's psychological state and exercise capacity and reduces mortality. Cardiac rehabilitation is defined as a process by which patients with cardiac disease are restored to their optimal physical, medical, psychological, social, emotional, vocational, and economic status. $^{2}$

\section{Exercise capacity}

Exercise capacity after myocardial infarction is impaired by the reduced response of cardiac output to exercise and the deconditioning effect of bed rest and physical inactivity. Some randomised and controlled studies have examined whether rehabilitation improves physical work capacity more than would be expected to occur spontaneously. ${ }^{3-7}$ The contradictory results probably relate to differences in exercise training programmes, the role of non-exercise treatment such as counselling, time of enrolment after infarction, and differences in the patient populations studied. Overall analysis of available data suggests that supervised physical exercise can be expected to increase a patient's maximal exercise capacity after infarction by an average of $15-25 \%$ over that which would occur spontaneously. ${ }^{8}$

Many, predominantly sedentary patients, without complications whose recreational and occupational activities are of low intensity resume their former activities without participating in a formal cardiac rehabilitation progamme. It is unclear, however, which patients are most likely to benefit. Hammond et al reported that the best predictor of improvement in exercise performance at one year was a low initial exercise capacity. ${ }^{9}$ But their results did not accord with those of Van Dixhoorn et al ${ }^{10}$ - perhaps because in the latter study $^{10}$ exercise capacity was not expressed as a percentage that predicted for age. A small improvement in exercise capacity might enable people with a poor exercise capacity after myocardial infarction to return to a reasonable level of activity. Cardiac rehabilitation may also benefit those with an initially good exercise capacity, though the improvement will be of less clinical importance.

The study by Goble $e t$ al reported in the March issue of the British Heart Journal showed that the physical benefits of aerobic exercise training can be as easily achieved with light exercise as with heavy exercise. ${ }^{11}$ The mechanism of the improvement in exercise capacity after cardiac re- habilitation is not clear. There is no totally objective method of assessing exercise capacity and hence increased patient motivation may result in an apparent improvement in physical state. Goble $e t$ al's study found that only $41 \%$ of patients who enrolled in the light exercise programme attended more than three quarters of their classes. Is the "improvement" in exercise capacity with both exercise regimes related to the type of exercise protocol or to reassurance of the patient by close, regular contact with a paramedical worker or doctor?

Most cardiac rehabilitation programmes have not evaluated the effects on patients with cardiac failure. Contrary to previously held belief, patients with severe left ventricular dysfunction who participated in an organised rehabilitation programme improved their exercise capacity. ${ }^{12} 13$ But those who have suffered a large anterior myocardial infarction (who might eventually develop overt heart failure) may deteriorate if enrolled in a rehabilitation programme soon after infarction. ${ }^{14}$

\section{Psychosocial function}

As expected, the results of the studies of the effects of cardiac rehabilitation and psychosocial function have been inconsistent. Psychosocial data are difficult to quantify. Reports in uncontrolled studies frequently describe a substantial improvement in psychological wellbeing related to cardiac exercise programmes. Data from the few randomised control studies suggest less impressive effects of exercise on psychological wellbeing and question whether the improvement documented relates to close review of the patient rather than participation in a formal exercise programme. ${ }^{15-18}$

No significant improvement was reported in occupational state in well designed assessments of cardiac rehabilitation. The conclusion of an extensive review on the subject was that special programmes of cardiac education, teaching, or psychological support and counselling over and above usual supportive care should not be recommended as routine measures after myocardial infarction. ${ }^{8}$ This is not to say, however, that selected patients might not require special teaching and counselling in addition to routine care because of psychological distress or a lack of knowledge.

\section{Mortality}

Once again, difficulties in study design have precluded definitive conclusions on mortality. Unfortunately, most studies have predominantly focused interventional effort on low risk patients. Consequently, because of a type II statistical error, studies of small groups of patients might 
"erroneously" conclude that rehabilitation fails to reduce mortality. Only one of the major randomised trials of exercise in cardiac rehabilitation after infarction reported a significant reduction in cardiac mortality. ${ }^{19}$ There were slightly more than 700 in the largest study..$^{20}$

This issue was reviewed by meta-analyses three times in the 1980s. May et al reviewed various interventions after myocardial infarction and reported a significant $19 \%$ decrease in cardiovascular mortality with an exercise programme. ${ }^{21}$ Oldridge $e t$ al and O'Connor et al combined the randomised exercise trials of the 1970s and 1980s (including over 2000 patients). ${ }^{22} 23$ Significantly lower pooled odds ratios -0.75 and 0.78 respectively-were reported. However, pooling of data in these studies might be inappropriate. There were differences in patient populations, mortality, and exercise programmes between studies. Given the presumed pathogenetic mechanisms involved in altering the atherosclerotic process it is unlikely that relatively short term programmes of exercise, for example less than four or five years, would substantially alter mortality and morbidity in patients with coronary artery disease. Perhaps a longer habitual increase in physical activity after infarction could reduce morbidity and mortality, as has been shown in certain long term studies of healthy people or in men originally at high risk from coronary disease as predicted by high concentrations of cholesterol, high blood pressure, or cigarette smoking. Such an assertion, however, currently cannot be supported by the existing data and must remain hypothetical.

\section{Risk factor modification}

When Kallio et al used a multifactorial intervention they found substantial changes in risk factors in their special intervention group. ${ }^{19}$ Other studies (not multifactorial but typically exercise only) showed less impressive or no changes in risk factors. On the basis of these studies an exercise programme alone seems unlikely to produce better risk factor outcomes when applied to unselected patients after myocardial infarction.

\section{Conclusions}

The analysis of the effects of cardiac rehabilitation is hampered by the heterogeneity of the patients studied. Formal exercise programmes are probably not justified for all patients. Certain patient subgroups may benefit, for example those with a low exercise capacity or chronic exercise limitation caused by severely depressed left ventricular function. The major beneficial effect of rehabilitation programmes may be associated with the reassurance provided by close contact with paramedical staff. Further trials are required to evaluate which components of the rehabilitation programme benefit the individual patient.

Department of Cardiology,

D P LIPKIN

The Royal Free Hospital,

Pond Street,

Hampstead, London NW3 $2 Q G$

1 Erb BD, Fletcher GF, Sheffield TL. Standards for exercise treatment programs. American Heart Association Subcommittee on Rehabilitation Target Activity Group. Circulation 1979;59:1084A-90A

2 Shanfield SB. Return to work after an acute myocardial infarction: a review. Journal of Critical Care 1990;19:109-17.

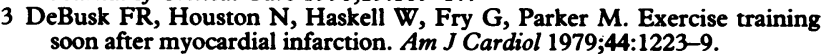

4 Miller NH, Haskell WL, Berra K, DeBusk RF. Home versus group exercise training for increasing functional capacity after myocardial infarction. Circulation 1984;70:645-9.

5 Carson P, Philips R, Lloyd M, et al. Exercise after myocardial infarction: controlled trial. $J R$ Coll Physicians Lond 1982;16:147-51.

6 Hung J, Gordon EP, Houston N, Haskell W, Goris M, DeBusk R. Change in rest and exercise myocardial perfusion and left ventricular function three to 26 weeks after clinically uncomplicated acute myocardial infarction: effects of exercise training. Am J Cardiol 1984;54:943-50.

7 Marra S, Paolillo V, Spadaccini F, Angelino PF. Long-term follow up after a controlled randomised post-infarction rehabilitation programme: effects on morbidity and mortality. Eur Heart $J 1985 ; 6: 656-63$.

8 Greenland P, Chu JS. Efficacy of cardiac rehabilitation services with emphasis on patients after myocardial infarction. Ann Intern Med 1988;109:650-63.

9 Hammond HK, Kelly TL, Froelicher VF, Pewen W. Use of clinical data in predicting improvement in exercise capacity after cardiac rehabilitation. J Am Coll Cardiol 1985;6:19-26.

10 Van Dixhoorn J, Duivenvoorden H, Pool J. Success and failure of exercise testing after myocardial infarction: Is the outcome predictable? $\mathrm{J}$ Am Coll Cardiol 1990;15:974-82.

11 Goble AJ, Hare DL, Macdonald PS, Oliver RG, Reid MA, Worcester MC. Effect of early programmes of high and low intensity exercise on physical performance after transmural acute myocardial infarction. Br Heart $J$ performance after

12 Conn EH, Williams RS, Wallace AF. Exercise responses before and after physical conditioning in patients with severely depressed left ventricular physical conditioning in patients with severe

13 Sullivan MJ, Higginbotham MB, Cobb FR. Exercise training in patients with severe left ventricular dysfunction: hemodynamic and metabolic effects. Circulation 1988;78:506-15.

14 Jugdutt BI, Michorowski BL, Kappagoda CT. Exercise training after anterior $Q$ wave myocardial infarction: importance of regional left ventricular function and topography. J Am Coll Cardiol 1988;12:362-72.

15 Mayou R. Effectiveness of cardiac rehabilitation. J Psychosom Res 1981; 25:423-7.

16 Mayou R, MacMahon D, Sleight P, Forencio MJ. Early rehabilitation after myocardial infarction. Lancet $1981 ;$ ii: $1399-401$

17 Stern MJ, Cleary P. The National Exercise and Heart Disease Project: longterm psychological outcome. Arch Intern Med 1982;142:1093-7.

18 Erdman RA, Duivenvoorden HJ. Psychologic evaluation of a cardiac rehabilitation program: a randomized clinical trial in patients with rehabilitation program: a randomized clinical trial in
myocardial infarction. $J$ Cardiac Rehab 1983;3:696-704.

19 Kallio V, Hamalainen H, Hakkila J, Luurila OJ. Reduction of sudden deaths by a multifactorial intervention program after acute myocardial infarction. Lancet $1979 ; \mathbf{i i}: 1091-4$.

20 Rechnitzer PA, Cunningham DA, Andrew GM, et al. Relation of exercise to the recurrence rate of myocardial infarction in men. Ontario Exercise Heart Collaborative Study. Am J Cardiol 1983;51:65-9.

21 May GS, Eberlein KA, Friberg CD. Secondary prevention after myocardial infarction. A review of long-term trials. Prog Cardiovasc Dis 1984;24: 331-51.

22 Oldridge NB, Guyatt GH, Fischer ME, Rimm AA. Cardiac rehabilitation after myocardial infarction. Combined experience of randomized clinical trials. JAMA 1988;260:945-50.

23 O'Connor GT, Buring JE, Yusuf S, et al. An overview of randomized trials of rehabilitation with exercise after myocardial infarction. Circulation 1989;80:234-44. 